\title{
A Program for Attracting and Recruiting Underrepresented Students
}

\author{
Rafic Bachnak, Carryn Bellomo, and Korinne Resendez \\ Texas A\&M University-Corpus Christi \\ Corpus Christi, TX 78412
}

\begin{abstract}
This paper describes a new program being implemented at Texas A\&M-Corpus Christi to improve the recruitment of underrepresented students. The program is designed to attract juniors in high schools to participate in summer workshops and a follow-up science and technology exhibit. Activities include field trips, hands-on experimentation, written and oral communications, and invited speakers. Faculty, students, professional organizations, and a number of manufacturing and processing industries are involved in the delivery of the program. The workshops are designed to introduce students to career opportunities, expose them to college life, involve them in hands-on educational activities, and encourage them to pursue careers in science and engineering technology. This paper describes the program and discusses the activities involved in its implementation.
\end{abstract}

\section{Introduction}

The current US workforce is comprised of 77\% White, 4\% Asian, and 19\% Minority. According to the Bureau of Labor Statistics and the National Science Foundation, however, among engineering professionals, $88 \%$ are White, $6 \%$ are Asian, and only $6 \%$ are minority [1]. To improve minority representation in engineering and engineering technology programs, institutions of higher education may use a number of approaches, such as the increase of visibility of the engineering profession, mentoring students, and academic support [2].

Texas A\&M-Corpus Christi (A\&M-CC) is a comprehensive urban university located on the South Texas Gulf Coast. The University is committed to identifying, recruiting, and retaining students who have high potential for academic success, especially those from groups who have been historically underrepresented in higher education and science. The Hispanic population of the University (37\%) lags far behind that of the surrounding areas $(69 \%)$. It is, therefore, imperative that A\&M-CC makes strong efforts to recruit and retain its Hispanic population despite the environmental odds of poverty, and inadequate educational preparation.

Strategies to recruit and retain students include hands-on approaches $[3,4]$, field trips $[5$, 6], summer workshops [7], and software training programs [8]. This paper describes a project that uses all these methods to attract underrepresented students to science and engineering through a program that includes presentations at high schools, invited 
speakers, field trips, hands-on laboratory activities, and science and technology exhibits ${ }^{1}$ [9]. Specifically, the program will involve attracting $11^{\text {th }}$ grade students to attend one of two two-week Science and Technology workshops. The workshops are designed to introduce students to job opportunities in the food industry and agriculture, expose them to college life, involve them in hands-on activities, and encourage them to major in science and engineering technology. Students will be recruited to participate in a followup Science and Technology Exhibit to be conducted during National Engineer's Week in February of each year. This program is unique in that it involves high school students in the $11^{\text {th }}$ grade. These students are ready to make decisions that affect them for the rest of their lives; selecting the college they wish to attend and choosing the field of study they want to pursue. It is anticipated that this innovative approach, focusing on the $11^{\text {th }}$ grade, can serve as a model for other Hispanic-Serving Institutions and for future national efforts. One of our goals is to make the activities undertaken by this project an integral part of the recruiting and training efforts and expand them to reach a larger geographical area and a higher number of underrepresented students.

\section{The Role of Technology}

The food industry has made great strides in using technologically sophisticated equipment. Technology has resulted, among other things, in greater diversity of food products and a more competitive domestic food industry with more export opportunities. It is imperative, however, that the supply of technically competent professionals be increased so that U.S. manufacturing plants remain competitive in the current world environment. Technicians, technologists, and engineers play an important role in employing and using technology. They are responsible for the design, testing, maintenance, and operation of various machines and systems such as conveyers, compressors, generators, microcontrollers, programmable logic controllers, microcomputers, processing equipment, inspection stations, freezers, grain processors, automatic feeding systems, global positioning systems, irrigation control, and packaging equipment. They also support and contribute to the quality, utilization, and safety of food products, including the development of quality control techniques, advanced processes, and packaging methods.

Institutions of higher education have recognized the important role of technology. At Purdue University, for example, the Agricultural and Biological Engineering Department introduced in 1998 a new course in Instrumentation and Data Acquisition [10]. Another course based on the $68 \mathrm{HC} 11$ microcontroller to teach industrial monitoring and control applications was developed in 1997 in the Agricultural and Biological Engineering Department at the University of Georgia [11].

\section{Partnerships and Collaborative Efforts}

The project involves collaboration between A\&M-CC, local high schools, local and regional professionals and industries, and local and regional institutions of higher

\footnotetext{
${ }^{1}$ This project is funded in part by the CSREES-USDA, award \# 2002-38422-12160

"Proceedings of the 2003 American Society for Engineering Education Annual Conference \& Exposition Copyright $@$ C 2003, American Society for Engineering Education"
} 
education. Volunteers from the food, agricultural, and other industries will be instrumental in identifying applications for training materials, organizing plant tours, mentoring students, serving as guest speakers, and implementing the Science and Technology Exhibit. Several local and regional companies have been very supportive of the project and a number of professionals have indicated their willingness to advise students, serve on the Science and Technology Exhibit Committee, participate as guest speakers, and/or serve as judges during the exhibit. Collaborators include major food processors, refineries, and manufacturing plants.

\section{Summer Workshops}

The summer workshops will introduce students to the agricultural and food industries, expose them to college life, involve them in hands-on educational activities, and encourage them to major in science and engineering technology. Each workshop includes four field trips, invited speakers, a tour of several university facilities (e.g., Bell Library, University Center, Computer Center, Science and Technology Laboratories, computer laboratories, etc.), demonstrations, hands-on experimentation, and oral presentations by students. Participants will tour the Science and Technology Laboratories, the Library, and other university facilities. The workshops will emphasize critical thinking and problem solving skills. Students will perform a series of laboratory exercises and carryout hands-on activities that involve automation systems. The laboratory exercises will demonstrate the workings of real devices and their use in real world applications. Planned daily breaks will allow social opportunities with other participants. Every student receives a free TI-83 Plus graphing calculator, teaching supplies, a per diem for lunch at the University Center Food Court, and a stipend of $\$ 300.00$. At the end of each workshop, each participant receives a certificate of accomplishment. The workshop schedule is shown in Table 1.

Table 1. Workshop schedule

\begin{tabular}{|c|c|c|c|c|}
\hline Week One & & & & \\
\hline & 9 to 12 & 12 to 1 & 1 to 3 & 3 to 5 \\
\hline Mon & Social & Lunch & Activities & Recreation \\
\hline Tue & Activities & Lunch & Presentations & Recreation \\
\hline Wed & Activities & Lunch & \multicolumn{2}{|l|}{ Field Trip } \\
\hline Thu & Activities & Lunch & Presentations & Recreation \\
\hline Fri & \multicolumn{4}{|l|}{ Field Trip (all day) } \\
\hline \multicolumn{5}{|l|}{ Week Two } \\
\hline & 9 to 12 & 12 to 1 & 1 to 3 & 3 to 5 \\
\hline Mon & Activities & Lunch & Presentations & Recreation \\
\hline Tue & Activities & Lunch & Field Trip & \\
\hline Wed & Activities & Lunch & Presentations & Recreation \\
\hline Thu & \multicolumn{4}{|c|}{ Field Trip (all day) } \\
\hline Fri & Activities & Lunch & Presentations & \\
\hline
\end{tabular}

High school students are made aware of the program via brochures, advertisement on the program web site [9], and presentations offered at local and regional high. Students apply for the summer workshops through their respective high school counselors or agriculture/science coordinators. Students from underrepresented groups will be chosen based on the applications they submit, with priority given to students from low-income and first-generation college-students. 
A graduate student assistant helps the directors with many tasks such as creating and maintaining a project web site, helping with the workshops and exhibits, and offering logistic support. An undergraduate student will be hired to help with the summer workshops. Also, this student and volunteers from engineering technology and other science majors will serve as role models and assist students in their social transition from their high school environments to the university environment. The following paragraphs briefly describe some tentative hands-on activities.

Exercise 1: Who turned out the lights?

Students will create a simple circuit comprised of two-way light switches, similar to a setup in a long hallway. Each switch will either turn the lights on or off.

Exercise 2: Who Says Xmas comes only once?

Students will program a PLC to flash trailing lights (one light after another) in a timed sequence. Students will learn about PLC applications in manufacturing plants.

Exercise 3: Gotcha!

Students will set up a small alarm system using PLCs. Alarm will go off when a set of switches is activated.

Exercise 4: How hot is that?

Students will use LabVIEW to convert temperature values from Celsius to Fahrenheit degrees.

Exercise 5: Virtual instruments made reality?

Students will run several LabVIEW demos. Examples include Robot, SimPhone, and Morse Code Generator.

Exercise 6: Hazardous waste!

Students will use a flow/level trainer to monitor the level in a tank. They will run a demo that controls the level under certain conditions.

Exercise 7: Sort them!

Students will run Computer Integrated Manufacturing (CIM) cell to sort parts coming down a conveyer belt.

Exercise 8: What is your temp?

Students will program a data logger to read and plot the temperature between the tips of their fingers. Plots will be generated in MATLAB or Excel.

Exercise 9: What is the Boiling Point?

Students will run demonstrations from the Distillation Expert Trainer (DEXTER) software. They will learn about temperature, pressure, and distillation.

Exercise 10: Let's cruise! 
Students will use Primedia software to learn about components of a control system. As an example, they will examine the cruise control system of a car.

Exercise 11: Graph it

Students will learn some MATLAB capabilities and create small program that graph useful functions.

\section{Exercise 12: 3-D designs}

Students will create three-dimensional drawings of several items using AutoCAD. This includes simple isometric and orthographic drawings of everyday objects.

Exercise 13: Let's race

Students will create miniature cars using molding machine. A competition will be part of this exercise.

Exercise 14: It is dark, sound the alarm

Students will create a light sensitive alarm circuit. When light no longer shines on the sensor a buzzer goes off.

Exercise 15: Identify yourself

Students will create a program that asks for their name. The entered name is compared to a list of workshop participants. If a name exists, the program displays associated information.

\section{Science and Technology Exhibit}

A Science and Technology Exhibit (STE) will be organized during National Engineer's Week of each year. A Science and Technology Exhibit Committee (STEC) that consists of volunteers from the food, agricultural, and other industries will be in charge of developing and implementing the exhibit.

The exhibit will be open to all interested high school students. Students who complete the summer workshops, however, will be encouraged to participate in the exhibit by assigning them to industry mentors who will guide the selection and implementation of projects. At the exhibit, a team of judges, consisting of six to eight professionals will determine the three winning projects. Awards will be as follows: $\$ 300.00$ for first place, $\$ 200.00$ for second place, and $\$ 100.00$ for third place.

\section{Program Results and Impact}

It is expected that this project will result in the following:

- 80 high school juniors will participate in one of four two-week Science and Technology workshops. Participants will become familiar with the role of science and engineering in advancing technologies.

- Presentations at high schools will introduce more than 800 students to the food 
industry and agriculture and the role of science and engineering in advancing these fields.

- The engineering technology programs will contribute to enhancing the food and agricultural scientific and professional work force by producing graduates who are well prepared to work in various industries.

- The College of Science and Technology, especially Engineering Technology, will be more effective in attracting, recruiting, and retaining underrepresented students.

To monitor the progress of the project, the following will be completed:

- Track the number of students that are made aware of the program, the number of students who apply to the workshops, the number of students who complete the workshops, and the number of students who participate in the exhibits.

- Survey students who participate in the first year workshops to determine whether or not the workshops are accomplishing their intended purpose. The feedback will be used to correct any deficiencies and improve the process. The same survey will be conducted again during the second summer.

- Survey all engineering technology students who started their studies within a year by the end of fall 2004 and fall 2005, to determine how many of them joined the program as a result, directly or indirectly, of this project.

- Survey workshop participants a year later to determine if they developed interest in the food and agricultural industries.

\section{Conclusion}

This paper described a program for attracting and recruiting underrepresented students. The program consists of summer workshops and a follow-up science and technology exhibit. The workshops are designed to introduce students to career opportunities, expose them to college life, involve them in hands-on educational activities, and encourage them to pursue careers in science and engineering technology. Activities include field trips, hands-on experimentation, written and oral communications, and invited speakers. Faculty, students, professional organizations, and a number of manufacturing and processing industries are all involved in the delivery of the program.

\section{Bibliography}

1. Rebecca Blust, "Increasing diversity within the field of engineering: Closing the minority gap," Proc. 2001 ASEE Annual Conf., Session 3249, CD-ROM, 10 pages, June 2001, Albuquerque, NM.

2. Willie Ofosu, "Improving minority representation in engineering programs," Proc. 2000 ASEE Annual Conf., Session 2670, CD-ROM, 6 pages, June 2000, St. Louis, MO.

3. Barbara Bratzel, Martha Cyr, and Ben Erwin, "Integration of data acquisition and analysis for elementary and middle school education," Proc. 2000 ASEE Annual Conf., Session 1359, CD-ROM, 6 pages, June 2000, St. Louis, MO.

"Proceedings of the 2003 American Society for Engineering Education Annual Conference \& Exposition Copyright $\odot$ 2003, American Society for Engineering Education" 
4. Radha Balamuralikrishna and Clfford Mirman, "Promoting engineering technology programs at the high school and middle school levels using hands-on approach," Proc. 2002 ASEE Annual Conf., CDROM, 9 pages, June 2002, Montreal, CA.

5. Mary Vollaro, "Field trips: An innovative approach in teaching Manufacturing Processes to traditional undergraduates," Proc. 2002 ASEE Annual Conf., CD-ROM, 6 pages, June 2002, Montreal, CA.

6. R. Bachnak, "Field trips: linking the classroom with industry," Proc. ASEE-GSW Annual Conf., Session 74C2, CD-ROM, 6 pages, April 2000, Las Cruces, NM.

7. Stephen Horan, "Introducing pre-college students and teachers to engineering via a summer enrichment program," Proc. 2001 ASEE Annual Conf., Session 2793, CD-ROM, 8 pages, June 2001, Albuquerque, NM.

8. Michael Symans, "Introducing middle school students to engineering principles using educational bridge design software,” Journal of Engineering Education, Vol. 89, No. 3, pp. 273-278, July 2000.

9. A Program for Attracting and Recruiting Underrepresented Students, Texas A\&M-Corpus Christi: http://www.sci.tamucc.edu/ entc/USDAgrant/index3.html.

10. Hartoon Sumali and Kristopher Delgado, "Instrumentation education in agricultural and biological engineering," Proc. 1998 ASEE Annual Conf., Session 2608, CD-ROM, 9 pages, June 1998, Seattle, WA.

11. T.K. Hamrita and R.W. McLendon, "A new approach for teaching microcontroller courses," Int. Journal on Engineering Education, Vol. 13, No. 4, pp. 269-274, 1997.

\section{Biography}

\section{RAFIC BACHNAK}

Rafic (Ray) Bachnak is an Associate Professor of Engineering Technology at Texas A\&M UniversityCorpus Christi. He received his B.S., M.S., and Ph.D. degrees in Electrical and Computer Engineering from Ohio University in 1983, 1984, and 1989, respectively. Dr. Bachnak was previously on the faculty of Franklin University and Northwestern State University.

\section{CARRYN BELLOMO}

Carryn Bellomo is an Assistant Professor of Mathematics at Texas A\&M Corpus Christi. She is a researcher in the field of Mathematical Biology. She graduated from Old Dominion University in 1998, after which she spent a year working for the DoD in combat systems and chemical/biological warfare. She has presented her research at several international conferences and published her work in several refereed journals.

\section{KORINNE RESENDEZ}

Korinne Resendez received her B.S. degree in Control Systems Engineering Technology from Texas A\&M University-Corpus Christi in May 2002. Ms. Resendez is currently pursuing a Master in Computer Science at A\&M-CC. 